\begin{tabular}{|c|l|}
\hline Title & Combining energetic profitability and cover effects to eval uate sal monid habitat quality \\
\hline Author(s) & Kawai, Hideyuki; Nagay ama, Shigeya; Urabe, Hirokazu; A kasaka, Takumi; Nakamura, Futoshi \\
\hline Citation & $\begin{array}{l}\text { Environmental Biology of Fishes, 97(5), 575-586 } \\
\text { https://doi.org/10.1007/310641-013-0217-4 }\end{array}$ \\
\hline Issue Date & 201405 \\
\hline Doc URL & http://hdl.handle.net/2115/60044 \\
\hline Rights & The final publication is available at Springer via http://dx.doi.org/10.1007/s10641-013-0217-4 \\
\hline Type & article (author version) \\
\hline File Information & Combining energetic profitability ....pdf \\
\hline
\end{tabular}

Instructions for use 


\title{
Combining energetic profitability and cover effects to evaluate
}

\author{
salmonid habitat quality
}

Authors

HIDEYUKI KAWAI ${ }^{1)}$, SHIGEYA NAGAYAMA ${ }^{13)}$, HIROKAZU URABE $^{2)}$, TAKUMI

AKASAKA $^{1)}$, and FUTOSHI NAKAMURA ${ }^{1)}$

1) Department of Forest Science, Graduate School of Agriculture, Hokkaido University, Kita

9 Nishi 9, Kita-ku, Sapporo 060-8589, Japan

2) Salmon and Freshwater Fisheries Research Institute, Kitakashiwagi, Eniwa, Hokkaido,

Japan

3) Current affiliation: Aqua Restoration Research Center, Public Works Research Institute,

Kawashimakasada, Kakamigahara, Gifu 501-6021, Japan

Corresponding author: Shigeya Nagayama

> Current affiliation $<<$

Aqua Restoration Research Center, Public Works Research Institute, Kawashimakasada,

Kakamigahara, Gifu 501-6021, Japan

E-mail: s-naga77@pwri.go.jp

Tel: +81-586-89-6036 Fax: +81-586-89-6039 


\section{Abstract}

Recent studies have demonstrated that the energetic profitability (net energy intake potential; NEI potential) of a habitat, which is calculated as the gross energy gain from foraging minus the energy expenditure from swimming at a focal point, may be a useful tool for predicting the salmonid biomass. The effectiveness of the NEI potential should be tested in various systems. Even if the NEI potential is validated, its predictive accuracy and transferability could be limited if the cover habitat, which is known to be an important factor for determining salmonid abundance, is not considered. We tested whether the NEI potential is effective for predicting the salmonid biomass even in a stream with abundant cover and whether combining the NEI potential and cover effects can improve the predictability of fish biomass using a generalized linear model. Our results demonstrated that the NEI potential could generally predict the fish biomass (percent deviance explained $=79.9 \%$ ), and the model that incorporated both the NEI potential and the cover ratio improved the predictive accuracy (percent deviance explained $=88.5 \%$ ). These results suggest that energetic profitability can be an effective indicator for assessing habitat quality and is relatively transferable to other systems. Furthermore, when cover effects are considered, the habitat quality is more accurately represented; thus, combining the energetic profitability and the cover effects might improve the transferability of the assessment across habitats.

Keywords: drift feeder, bioenergetics model, cover, salmonid biomass, habitat assessment 


\section{Introduction}

Freshwater habitats have been severely degraded by various human activities (Behnke 1990; Dynesius and Nilsson 1994), and habitat degradation has played a key role in the decline of salmonid populations (Gregory and Bisson 1997). Salmonid populations are valuable for commercial and recreational fishing and promote the maintenance of stream ecosystems. Numerous studies have focused on assessing habitat quality to recover and conserve salmonid populations (see Fausch 1988 and Rosenfeld 2003 for reviews). The most common approach involves identifying the physical habitat features that regulate salmonid populations. Several models have represented fish abundance as a function of these physical habitat variables (Fausch et al. 1988); however, these models were based on observational data, which frequently vary among study locations (Inoue et al. 1997). As a result, models obtained in a particular location are typically not easily applied to other systems (Fausch et al. 1988; Bourgeois et al. 1996).

Habitat models have been developed based on fish preferences for microhabitat variables, such as the current velocity, depth, substrate size, and distance from cover at the focal point, and these models have generally been successful in assessing habitat quality under particular conditions (e.g., Urabe and Nakano 1999; Guay et al. 2000; Mäki-Petäys et al. 2002; Guay et al. 2003). However, the preference-based approach does not consider prey availability, which is a factor that significantly affects habitat quality (Cada et al. 1987;

Filbert and Hawkins 1995; Nislow et al. 1998; Giannico 2000; Imre et al. 2004). Therefore, the applicability of the preference-based approach to other systems with different prey 
productivity is limited (Rosenfeld et al. 2005; see Mäki-Petäys et al. 2002 for an alternative view).

An alternative approach that combines both the physical habitat and prey availability in evaluating habitat has emerged from studies focusing on energetic profitability (Net energy intake potential; NEI potential) of a habitat, which is estimated as the gross energy gain from foraging minus the energy expenditure from swimming at a focal point using a bioenergetics model (Fausch 1984; Hughes and Dill 1990). These and other studies (Hughes 1992a; Hughes 1992b; Guensch et al. 2001; Hayes et al. 2007; Jenkins and Keeley 2010) have demonstrated that fish consistently distribute themselves in a way that maximizes their NEI potential (Fausch 1984; Hughes 1992a; Hughes 1992b). A direct linkage between the NEI potential of habitats and the growth rate, a critical component of fitness, has also been indicated (Nislow et al. 1999; Nislow et al. 2000; Nislow et al. 2004; Rosenfeld and Boss 2001; Rosenfeld et al. 2005). From these studies, we can hypothesize that a greater abundance of high-NEI-potential (energetically profitable) positions in a given area of a stream may result in a higher fish biomass because the number and/or size of the fish will be greater.

This relationship might be more robust and transferable than that reported by conventional approaches. In fact, recent studies conducted in other regions, where the environmental background differed greatly from those in the original studies, reported that the NEI potential of a given stretch of stream was closely correlated with the fish biomass (Hayes et al. 2007; Jenkins and Keeley 2010; Urabe et al. 2010). Although additional studies are necessary to validate and refine these findings, the studies cited here suggest that 
a bioenergetics model would be a significant tool for habitat management.

However, approaches based on the energetic profitability (NEI potential) of a habitat are still imperfect for assessing habitat quality because the NEI potential does not consider the effect of cover on individual fitness. Cover can increase fitness by reducing the predation mortality (Helfman 1981), providing velocity refuges (Fausch 1993), and mitigating the competitive interactions among individuals at some age classes by visual isolation (Fausch 1993; Imre et al. 2002). Therefore, the combination of cover effects and the NEI potential may represent a better approach for assessing habitat quality. In the present study, we tested whether the NEI potential is effective for predicting the salmonid biomass even in a stream with abundant cover and whether the combination of the NEI potential and cover abundance can serve as a better predictor of habitat quality.

\section{Materials and methods}

Study site

The study was conducted in the Ironnebetsu Stream (channel length of $15.1 \mathrm{~km}$; watershed area of $38.8 \mathrm{~km}^{2}$ ), a small tributary of the Musa River in the Shibetsu River watershed, northern Japan (Fig. 1). The Ironnebetsu Stream is dominated by a pebble and cobble substrate and broadleaf forest cover in the riparian zones. The width of the study reaches was $2.9 \pm 0.85 \mathrm{~m}$ (mean $\pm \mathrm{SD}$ ), the depth was $29.8 \pm 11.9 \mathrm{~cm}$, the current velocity was 44.5 $\pm 15.8 \mathrm{~cm} / \mathrm{s}$, and the bed slope was $0.9 \pm 0.2 \%$, which were generally suitable habitat 
features for stream salmonids. The study reaches were meandering channels with pool-riffle sequences. Undercut banks and accumulated woody debris were present, particularly at the outer bends of the reaches. Although masu salmon (Oncorhynchus masou Brevoort), which typically become smolt at the age $1+$, is the dominant native species in the Ironnebetsu Stream, other salmonid species, such as Dolly Varden (Salvelinus malma Walbaum), white-spotted char (S. leucomaenis Pallas), and rainbow trout (O. mykiss Walbaum), are also present. The biomass of all four of these salmonids was used in the present analysis. Fishing is strictly prohibited year-round to preserve and enhance the masu salmon stock in the Musa Stream drainage, including the Ironnebetsu Stream.

We established four study reaches (200 m in length) in the Ironnebetsu Stream (Reaches 1-4 in Fig. 1) and selected nine to ten channel units in each of the study reaches (riffle: $\mathrm{n}=19$, pool: $\mathrm{n}=19$, unit length: $5-10 \mathrm{~m}$ ). We surveyed fish populations and measured the physical attributes of each channel unit. In each reach, drifting invertebrates were collected at one riffle unit that was considered to be representative of the study reach (see "Drift sampling"). The field surveys were conducted from late July to early August 2008 during the summer base flow, when the stream temperature and flow regime were relatively stable.

Measurement of physical variables

We measured the physical parameters that were essential for calculating the NEI potential of the study channel units: the current velocity at $60 \%$ of the depth, the bottom current velocity, 
and the depth [see Table 1 and Equations (1)-(4)]. In each channel unit, the current velocity and depth were quantified at five equally spaced points at $1 \mathrm{~m}$ intervals on transects that were perpendicular to the flow of the stream (Fig. 2a). As a result of this procedure, approximately $1 \mathrm{~m} \times 0.5 \mathrm{~m}$ grids were generated in the study units. This system's spatial resolution for assessing the habitat quality was nearly equivalent to the size of the territories of juvenile stream salmonids (Keeley and McPhail 1998). The current velocity was measured using a portable electromagnetic flow-meter (Flow-MATE Model 2000; Marsh-McBirney Inc., Frederick, MD, USA).

We also quantified the cover area in each channel unit. Woody materials, grasses, and undercut banks (both below the water surface and up to $40 \mathrm{~cm}$ above the water surface) were defined as cover in the present study. The area of each cover feature was calculated by multiplying the cover length and the average cover width (Fig. 2b) and summing the cover area. The average cover width was the mean of three widths at $1 / 4,1 / 2$, and $3 / 4$ of the cover length (Fig. 2b). Ultimately, the cover ratio (total cover area: channel unit area) was used for the data analysis and model construction.

Drift sampling

To estimate the prey density, we collected drifting invertebrates at a riffle in each study reach. The sampling points were set at riffles characterized by the average physical conditions (width, current velocity, and depth) near the center of each study reach. The study reaches were short (200 $\mathrm{m}$ in length), and their surrounding environments were relatively uniform. 
Therefore, we regarded the drift samples as representative of each study reach. These samples were used to calculate the NEI potential for each channel unit. The drifting invertebrates were sampled according to the methods of Urabe et al. (2010). Four drift nets $(600 \mu \mathrm{m}$ mesh, $25 \mathrm{~cm}$ $\times 25 \mathrm{~cm}$ mouth openings, and $1 \mathrm{~m}$ net length) were arrayed near the center of the stream flow for 60 minutes (Fig. 2c). The proportions of the total widths of the four nets to the stream widths at the sampling points were calculated to confirm the efficiency of the drift sampling. The openings were set to extend more than $3 \mathrm{~cm}$ above the water surface to capture the floating terrestrial invertebrates. Drifting density is generally stable during the daytime (e.g., Smock 2006; Miyasaka and Nakano 1999). Thus, we sampled the drift between 0530 and $0600 \mathrm{~h}$ (approximately $1 \mathrm{~h}$ after sunrise) and regarded these samples as representative of the prey condition in each reach. The water volume that was sieved by the nets was estimated from the current velocity measured at $60 \%$ of the depth, the total area of the opening below the water surface, and the collection time. We also recorded the current velocity in front of the nets at the beginning and end of the collection. We compared the velocities to estimate the filtering efficiency of each net (i.e., the ratio of the velocities at the beginning and end of the collection). All of the samples were preserved in $99 \%$ ethanol and analyzed in the laboratory. The invertebrate body lengths were measured under a microscope. The invertebrates were dried at $55{ }^{\circ} \mathrm{C}$ for $24 \mathrm{~h}$ and weighed to the nearest $0.1 \mathrm{mg}$. The prey density for each net was calculated by dividing the total dry weight by the water volume sieved by the nets.

Fish population survey 
The fish were captured in each channel unit using a backpack electrofishing unit (Model 12A, Smith-Root Inc., Vancouver, WA, USA). The number of each salmonid species in each channel unit was estimated using the three-pass removal method (Carle and Strub 1978). We also measured the weights $(\mathrm{g})$ and the fork lengths $(\mathrm{cm})$ of the captured fish. The biomass of each species was calculated from the estimated number of fish and the mean body weight, and the sum of the biomass was defined as the total biomass in the unit. Stream salmonids generally require similar habitats (Bjornn and Reiser 1991) and partition identical resources (i.e., habitat capacity) through intra and/or interspecific competition in the sympatric area (Nakano and Furukawa-Tanaka 1994; Nakano 1995). Therefore, the use of the total salmonid biomass was reasonable to evaluate the salmonid carrying capacity of the reaches. Dolly Varden may shift prey from drifting to benthic items in the presence of other salmonids (Fausch et al. 1997; Nakano et al. 1999). However, the effects of such biological traits on our analysis were likely negligible because most of the captured fish were masu salmon and not Dolly Varden (3.8\% of all fish).

Description of the bioenergetics model

The bioenergetics model used to estimate the NEI potential in this study is a simple cost-benefit foraging model (Table 1). The NEI potential is expressed as the difference between the gross energy intake (GEI) from the prey resources and the swimming cost (SC) required to remain at the focal point (Fausch 1984, Hughes and Dill 1990). The NEI potential at a given point $i\left(\mathrm{NEI}_{i}\right)$ is calculated from the following equations: 
$\mathrm{NEI}_{i}=\mathrm{GEI}_{i}-\mathrm{SC}_{i}$

$\mathrm{GEI}_{i}=\mathrm{CA}_{i} \cdot \mathrm{V}_{\mathrm{fg}, i} \cdot \mathrm{D} \cdot \mathrm{PE} \cdot 3,600 / 10^{9}$

where $\mathrm{CA}_{i}$ and $\mathrm{V}_{\mathrm{fg}, i}$ are the capture (foraging) area $\left(\mathrm{cm}^{2}\right)$ and the current velocity $(\mathrm{cm} / \mathrm{s})$ at foraging point $i$, respectively, and $\mathrm{D}$ and PE are the prey density $\left(\mathrm{mg} / \mathrm{m}^{3}\right)$ and prey energy content $(\mathrm{J} / \mathrm{g})$, respectively, based on the dry weight of the prey. Because most of the drift invertebrates belonged to the class Insecta (98\% of the total prey weight), we used $20,189 \mathrm{~J} / \mathrm{g}$ (from Cummins and Wuycheck 1971) as the PE value. The $\mathrm{CA}_{i}$ shape can be specified by one of five possible patterns and is dependent on the water depth, the current velocity, and the maximum capture distance $\left(\mathrm{MCD}_{i}\right)$ at the focal point (Urabe et al. 2010). The $\mathrm{CA}_{i}$ shapes and the $\mathrm{MCD}_{i}$ definition are presented in Fig. 3. The two basic $\mathrm{CA}_{i}$ patterns are represented by the following equations:

$\mathrm{CA}_{i}=\pi\left(\mathrm{MCD}_{i}\right)^{2} / 2+2 \cdot 3 \cdot\left(\mathrm{MCD}_{i}\right)$

and

$\mathrm{CA}_{i}=\pi\left(\mathrm{MCD}_{i}\right)^{2}$

Equations 3 and 4 correspond to patterns 1 and 3, respectively (Fig. 3). Pattern 1 is used when the depth is greater than the MCD and the fish are at the bottom. Pattern 3 is used when fish at $60 \%$ depth display a shorter MCD than the distance from the fish to the water surface and stream bed. Pattern 2 is a semicircle that is partially truncated by the stream surface (Fig. 3a). Pattern 4 is a circle truncated by the stream bed, and pattern 5 is a circle truncated by both the water surface and the stream bed (Fig. 3b).

The transected measurement points (see "Measurement of physical variables" in this section) were regarded as the virtual focal points, and the NEI potential was calculated at each 
focal point (Fig. 2a). The NEI potential was averaged in each channel unit and used for the analysis. We selected the best equation to calculate the $\mathrm{CA}_{i}$ for each measurement point based on the relationship between the focal point current velocity $\left(\mathrm{V}_{\mathrm{fp}, i}\right)$, the foraging point current velocity $\left(\mathrm{V}_{\mathrm{fg}, i}\right)$, the $\mathrm{MCD}_{i}$, and the depth ${ }_{i}$. Of the two current velocities (the current at the bottom and at $60 \%$ of the depth) at each measurement point, we specified the slower current velocity as $\mathrm{V}_{\mathrm{fp}, i}$ and the faster velocity as $\mathrm{V}_{\mathrm{fg}, i}$. The fork length (FL) and body weight (BW) of the salmonids, the prey length (PL), and the prey density (D) obtained from the field surveys were used to calculate the $\mathrm{NEI}_{i}$ (Table 1). The FL and BW were defined as the means of all of the individuals of all salmonid species for each unit. The PL and D were defined as the means of the four sampling nets from each study reach. All of the equations or values used to calculate the NEI potential are presented in Table 1.

To calculate the NEI potential, we assumed that the fish foraged on all of the drifting prey that passed through the capture area. Based on previous studies that demonstrated that foraging success can vary with the current velocity and foraging distance (Grossman et al. 2002; Hughes et al. 2003; Piccolo et al. 2008), our assumption may yield an overestimate of the NEI potential; thus, the NEI potential value from the present model is only an estimate. However, previous studies have demonstrated that models that did not consider the capture probability effectively estimated fish position choice and abundance (e.g., Hughes and Dill 1990; Guensch et al. 2001; Jenkins and Keeley 2010; Urabe et al. 2010). This finding implies that the calculations using an approximate estimate are acceptable for a relative comparison of the NEI potential among sites.

Based on these assumptions and equations, we calculated the NEI potential for each 
measurement point, and the average NEI potential was estimated for each unit. In the calculations of the average NEI potential, negative values were treated as 0 because they are meaningless for fish.

Data analysis

We built three generalized linear models (GLMs; Crawley 2002) with the observed salmonid biomass as the dependent variable and either the NEI potential, the cover ratio, or both as the independent variable(s) (error distribution, Gaussian; link function, identity). Consequently, three GLMs (NEI potential, cover ratio, and full models) were produced. Using these GLMs, we tested whether the NEI potential effectively predicted the salmonid biomass even in the presence of abundant cover and whether considering the cover effects contributed to an improved predictive accuracy of the fish biomass. Urabe et al. (2010) demonstrated that the relationship between the salmonid biomass and the NEI potential was expressed as a power function, likely due to the density effect. Therefore, we adopted the NEI potential as a power term, and its index varied from 0.0 to 1.0 (one decimal place). Although salmonid abundance generally increases with cover ratio, excess cover may negatively impact the salmonid biomass by reducing foraging efficiency (Wilzbach et al. 1986). Therefore, we adopted the full model with a quadratic cover term:

Fish biomass $=\mathrm{a}(\mathrm{NEI})^{\mathrm{b}}+\mathrm{c}(\text { cover })^{2}+\mathrm{d}($ cover $)$ 
The model was selected using the corrected Akaike Information Criterion (AICc) (Burnham and Anderson 1998) in a best-subset selection procedure. Both the quadratic and linear terms were incorporated into the cover ratio model. When the models displayed a similar explanatory power $(\triangle \mathrm{AICc}<2)$, the model with the lowest AICc was selected as the best model. To confirm the fit of the best model, we assessed the percent deviance that could be explained by the model [100 $\times(1$ - residual deviance / null deviance $)]$ (see Dobson 1999) and the relationship between the observed and predicted values. If the full model was selected as the best model, we compared the $\triangle \mathrm{AICc}$ between the models from which either the NEI potential or the cover ratio was removed to determine which variable exerted a greater influence on the prediction. All of the statistical analyses were performed using the statistics package R, version 2.10.1 (R Foundation for Statistical Computing, Vienna, Austria).

\section{Results}

The drift sampling efficiencies were high for all of the nets. The ratio of the current velocity at the end of the collection period to the current velocity at the beginning of the period was $0.988 \pm 0.066$ (mean $\pm \mathrm{SD}$ ), and the proportion of the total widths of the four nets to the stream width at each sampling point was relatively consistent among all reaches $(29,33,38$, or $43 \%$ at each sampling point). These conditions allowed us to evaluate the abundance of the drifting prey. The PL and D for each study reach ranged from 3.65-4.13 $\mathrm{mm}$ and 0.0572-0.0709 mg/m $\mathrm{m}^{3}$, respectively (Tables 1 and 2). The fish biomass ranged from 
$0.05-43.03 \mathrm{~g} / \mathrm{m}^{2}$ in each channel unit (Table 2). Masu salmon were the most abundant fish captured (93\% of all fish), and 97\% of them were the young-of-the-year (FL: 27-104 mm). The mean FL and BW in the study units ranged from 37.7-101.0 $\mathrm{mm}$ and $0.60-21.91 \mathrm{~g}$, respectively (Table 1 ). The cover ratio was $25.5 \pm 24.4 \%$ (mean $\pm \mathrm{SD}$ ), with a range of 0-90.3\%, and the estimated NEI potential was $138.0 \pm 88.0 \mathrm{~J} / \mathrm{h}$, with a range of 11.2-394.8 $\mathrm{J} / \mathrm{h}$ (Table 2).

The following full model displayed the lowest AICc and was selected as the best model to predict the salmonid biomass (Table 3): fish biomass $=0.46 \times(\text { mean NEI })^{0.6}-54 \times$ $(\text { cover })^{2}+60 \times($ cover $)$. Although the explanatory power was equivalent for the models with NEI exponents ranging from 0.3 to $0.8(\triangle \mathrm{AICc}<2)$, the model with an exponent of 0.6 displayed the lowest AICc. The predictability of the NEI potential model as well as the full model was generally high. However, the percent deviance explained by the full model (88.5\%) was higher than that explained by the NEI potential model (79.9\%) and the values predicted by the full model exhibited a better fit to the observed values than the predictions of the NEI potential model (Fig. 4). The NEI potential model overestimated the salmonid biomass in the channel units with a low cover ratio, whereas it underestimated the biomass for the units with a high cover ratio (Fig. 4a). The best model, which incorporated the cover factors, improved the estimations (Fig. 4b). The $\triangle \mathrm{AICc}$ was higher when the cover ratio parameters were removed from the full model $(\triangle \mathrm{AICc}=16.3)$ than when the NEI potential was removed $(\triangle \mathrm{AICc}=14.0)$.

\section{Discussion}


In agreement with recent studies (Nislow et al. 2004; Hayes et al. 2007; Jenkins and Keeley 2010; Urabe et al. 2010), we demonstrated that the energetic profitability of the habitat is an effective basis for estimating salmonid biomass [Fig. 4a (percent deviance explained = 77.9\%)]. This observation suggests that the NEI potential can be used to effectively evaluate the habitat quality in our study system, even though the environmental conditions at our site might differ significantly from those in other studies. Previous studies have demonstrated that fish selectively use a focal point with a high NEI potential (Fausch 1984; Hughes and Dill 1990; Guensch et al. 2001; Jenkins and Keeley 2010) and that such positions produce high individual growth rates (Fausch 1984; Nislow et al. 2000; Rosenfeld et al. 2005). Growth during the summer strongly affects winter survival (Hunt 1969; Smith and Griffith 1994) and reproductive population traits, such as the age at which fish become smolt (Metcalfe and Thorpe 1990). These findings suggest that the NEI potential during the summer may be a key determinant of the local population level across various systems.

We also observed that the effect of the cover ratio on the fish biomass were stronger than that of the NEI potential. Consequently, the predictability of the model was enhanced by combining the NEI potential and the cover ratio [Fig. $4 \mathrm{~b}$ (percent deviance explained = $88.5 \%)$ ]. In general, functions of cover are categorized into three types: providing shelter from (1) current velocity and (2) predators and (3) mitigating the competition intensity among individuals at some age classes. Cover creates a low-current-velocity area by intercepting the fast water current (Nagayama et al. 2009). Focal points with a low current velocity reduce the swimming cost and enhance the profitability of a foraging position 
(Fausch 1993). The positive effects of velocity shelter on habitat quality have been evaluated already as the NEI potential. Therefore, the improved predictive ability of the full model that combines the NEI potential and the cover ratio was likely to be attributed to the other two effects of cover.

Overhead and lateral cover types are most likely to provide shelter from terrestrial and aquatic predators (Helfman 1981; Fausch 1993; Lonzarich and Quinn 1995; Spalding et al. 1995), and lateral cover can also visually isolate individuals and reduce the level of interference (Fausch 1993; Imre et al. 2002). These cover functions contribute to an increase in the availability of energetically profitable foraging positions. In the present study, we observed that when the fish biomass was predicted using only the NEI potential, it tended to be underestimated at reaches with abundant cover and overestimated at reaches with little cover (Fig. 4a); these estimation errors were remedied by incorporating cover ratio (Fig. 4b). When the predation pressure and competitive intensity among individuals are higher due to scarce-cover conditions, fish cannot always use the profitable position even if it is present, which likely results in the overestimation of fish biomass by the NEI potential model. In contrast, the use of the profitable position by fish might be facilitated under the abundant-cover conditions. Thus, we concluded that the cover structures could enhance the carrying capacity via an increase in the availability of energetically profitable positions for fish.

Although combining energetic profitability and cover effects would represent a more biologically meaningful approach to assessing habitat quality and thus may be more transferable across different systems than the conventional approach, some technical 
problems persist. For example, the fish size influences the calculation of the NEI potential through the estimation error of the MCD. Consequently, an increased size variation would decrease the accuracy of the prediction. At our study site, almost all of the captured fish were young-of-the-year masu salmon (>90\%), and our system assumed that all of the fish in a channel unit were the same size. However, in reality, salmonid populations often comprise multiple size (age) classes and species. In addition, the potential importance of cover among stream-dwelling salmonids could vary depending on the food availability (Wilzbach 1985; Railsback et al. 2005) and presumably on the intensity of the predation pressure. These factors imply that the effect of cover on the fish biomass demonstrated by our model is not necessarily consistent across all systems. However, we propose that the NEI potential represents an important indicator for assessing the habitat quality for stream-salmonids during the summer. Additionally, considering the cover effects can enhance the effectiveness of the NEI potential as an indicator of the salmonid habitat quality in a particular situation. We believe that this result will help develop a new method for assessing the habitat quality that can be extended to the watershed scale and transferred across various systems.

To apply our findings to watershed management practices, factors affecting the NEI potential, such as the size structure of the fish (Jenkins and Keeley 2010), prey abundance (Railsback and Rose 1999), prey availability (Hughes et al. 2003; Hayes et al. 2007; Piccolo et al. 2008), temperature (Jenkins and Keeley 2010), and flow regime (Nislow et al. 2004; Railsback et al. 2006; Hayes et al. 2007), should also be considered. To obtain a comprehensive understanding of the complex effects of these factors on the NEI potential 
using only our approach would be extremely difficult. Process-based bioenergetics model (Hayes et al. 2007), which incorporates the effects of variations in spatio-temporal hydraulic and biological factors on the energetic profitability of local habitats, could greatly contribute to the understanding of the combined effects of those factors on the habitat quality. Hydraulic simulation studies, which have been employed in PHABSIM studies, can simulate the depth and velocity in any watershed locations (Beecher et al. 2002; Beecher et al. 2010) and thus could expand the potential of the process-based bioenergetic approach. In addition, combining the existing inventory data of habitat features (e.g., cover abundance and river width) with this approach would improve the management of watersheds.

\section{Acknowledgments}

We are grateful for the support of the Grants in Aid for Scientific Research (No. 19208013) from the Ministry of Education, Science, and Culture, Japan, and for the grant from the Environment Research and Technology Development Fund (S9 and 4D-1201) from the Ministry of the Environment, Japan. We also thank the graduate students, particularly T. Seno and N. Ishiyama, Hokkaido University, for their assistance in conducting the fieldwork. This research was conducted in accordance with the appropriate animal care guidelines.

\section{References}


Beecher HA, Caldwell BA, DeMond SB (2002) Evaluation of depth and velocity

preferences of juvenile coho salmon in Washington streams. N Am J Fish Manage 22: $785-795$

Beecher HA, Caldwell BA, DeMond SB, Seiler D, Boessow SN (2010) An empirical assessment of PHABSIM using long-term monitoring of coho salmon smolt production in Bingham Creek, Washington. N Am J Fish Manage 30: 1529-1543

Behnke AC (1990) A perspective on America's vanishing streams. J N Am Benthol Soc 9: $77-88$

Bjorn TC, Reiser DW (1991) Habitat Requirements of Salmonids in Streams. In: Meehan WR (ed) Influences of Forest and Rangeland Management on Salmonid Fishes and Their Habitats. Special Publication 19. American Fisheries Society, Bethesda, pp 83-138 Bourgeois G, Cunjak RA, Caissie D, El-Jabi N (1996) A spatial and temporal evaluation of PHABSIM in relation to measured density of juvenile atlantic salmon in a small stream. N Am J Fish Manage 16: 154-166

Burnham KP, Anderson DR (1998) Model selection and inference: a practical information-theoretic approach. Springer, Berlin

Cada GF, Loara JM, Sale MJ (1987) Evidence of food limitation of rainbow and brown trout in southern Appalachian soft-water streams. Trans Am Fish Soc 116: 692-702

Carle FL, Strub MR (1978) A new method for estimating population size from removal data. Biometrics 34: 621-630.

Crawley M (2002) Statistical computing: an introduction to data analysis using Splus. Wiley, London 
Cummins KW, Wuycheck JC (1971) Caloric equivalents for investigations in ecological energetics. Mitt Int Ver Theor Angew Limnol 18: 1-158

Dobson A (1999) An introduction to generalized liner models. Chapman, London

Dynesius M, Nilsson C (1994) Fragmentation and flow regulation of river systems in the northern third of the world. Science 266: 753-762

Fausch KD (1984) Profitable stream positions for salmonids: relating specific growth rate to net energy gain. Can J Zoolog 62: 441-451

Fausch KD (1988) Tests of competition between native and introduced salmonids in streams: what have we learned? Can J Fish Aquat Sci 45: 2238-2246

Fausch KD (1993) Experimental analysis of microhabitat selection by juvenile steelhead (Oncorhynchus mykiss) and coho salmon (O.kisutch) in a British Columbia stream. Can J Fish Aquat Sci 50: 1198-1207

Fausch KD, Nakano S, Kitano S (1997) Experimentally induced foraging mode shift by sympatric charrs in a Japanese mountain stream. Behav Ecol 8: 414-420

Filbert RB, Hawkins CP (1995) Variation in condition of rainbow trout in relation to food, temperature, and individual length in the Green river, Utah. Trans Am Fish Soc 124: $824-835$

Giannico GR (2000) Habitat selection by juvenile coho salmon in response to food and woody debris manipulations in suburban and rural stream sections. Can J Fish Aquat Sci 57: 1804-1813

Gregory SV, Bisson PA (1997) Degradation and loss of anadromous salmonid habitat in the Pacific Northwest. In: Stouder DJ, Bisson PA, Naiman RJ (eds) Pacific salmon and 
their ecosystems: status and future options. Chapman \& Hall, New York, pp 277-314

Grossman GD, Rincon PA, Fair MD, Ratajczak RE Jr. (2002) A new optimal foraging model predicts habitat use by drift-feeding stream minnows. Ecol Freshw Fish 11: $2-10$

Guay JC, Boisclair D, Leclerc M, Lapointe M (2003) Assesment of the transferability of biological habitat models for Atlantic salmon parr (Salmo salar). Can J Fish Aquat Sci 60: $1398-1408$

Guay JC, Boisclair D, Leclerc M, Lapointe M, Legendre P (2000) Development and validation of numerical habitat models for juveniles of Atlantic salmon (Salmo salar). Can J Fish Aquat Sci 57: 2065-2075

Guensch GR, Hardy TB, Addley RC (2001) Examining feeding strategies and position choice of drift-feeding salmonids using an individual-based, mechanistic foraging model. Can J Fish Aquat Sci 58: 446-457

Hayes JW, Hughes NF, Kelly LH (2007) Process-based modelling of invertebrate drift transport, net energy intake and reach carrying capacity for drift-feeding salmonids. Ecol Model 207: 171-178

Helfman GS (1981) The advantage to fish of hovering in shade. Copeia 1981: 392-400 Hughes NF (1992a) Ranking of positions by drift-feeding arctic grayling (Thymallus arcticus) in dominance hierarchies. Can J Fish Aquat Sci 49: 1994-1998

Hughes NF (1992b) Selection of positions by drift-feeding salmonids in dominance hierarchies: model and test for arctic grayling (Thymallus arcticus) in subarctic mountainstreams, interior Alaska. Can J Fish Aquat Sci 49: 1999-2008 
Hughes NF, Dill LM (1990) Position choice by drift-feeding salmonids: model and test for Arctic grayling (Thmallus arcticus) in subarctic mountain streams, interior Alaska. Can J Fish Aquat Sci 47: 2039-2048

Hughes NF, Hayes JW, Shearer KA, Young RG (2003) Testing a model of drift-feeding using three-dimensional videography of wild brown trout, Salmo trutta, in a New Zealand river. Can J Fish Aquat Sci 60: 1462-1476

Hunt RL (1969) Overwinter survival of wild fingerling brook trout in Lawrence Creek, Wisconsin. J Fish Res Board Can 26: 1473-1483

Imre I, Grant JW, Keeley ER (2002) The effect of visual isolation on territory size and population density of juvenile rainbow trout (Oncorhynchus mykiss). Can J Fish Aquat Sci 59: 303-309

Imre IJ, Grant WA, Keeley ER (2004) The effect of food abundance on territory size and population density of juvenile steelhead trout (Oncorhynchus mykiss). Oecologia 138: $371-378$

Inoue M, Nakano S, Nakamura F (1997) Juvenile masu salmon (Oncorhynchus masou) abundance and stream habitat relationships in northern Japan. Can J Fish Aquat Sci 54: $1331-1341$

Jenkins RA, Keeley ER (2010) Bioenergetic assessment of habitat quality for stream-dwelling cutthroat trout (Oncorhynchus clarkii bouvieri) with implications for climate change and nutrient supplementation. Can J Fish Aquat Sci 67: 371-385

Keeley ER, McPhail JD (1998) Food abundance, intruder pressure, and body size as determinants of territory size in juvenile steelhead trout (Oncorhynchus mykiss). 
Behaviour 135: 65-82

Lonzarich DG, Quinn TP (1995) Experimental evidence for the effect of depth and structure on the distribution, growth, and survival of stream fishes. Can J Zoolog 73:

$2223-2230$

Mäki-Petäys A, Huusko A, Erkinaro J, Muotka T (2002) Transferability of habitat suitability criteria of juvenile Atlantic salmon (Salmo salar). Can J Fish Aquat Sci 58: 218-228

Metcalfe NB, Thorpe JE (1990) Determinants of geographical variation in the age of seaward-migrating salmon, Salmo salar. J Anim Ecol 59: 135-145

Miyasaka H, Nakano S (1999) Effects of drift- and benthic-foraging fish on the drift dispersal of three species of mayfly nymphs in a Japanese stream. Oecologia 118: 99-106

Nakano S (1995) Individual differences in resource use, growth, and emigration under the influence of a dominance hierarchy in fluvial red-spotted masu salmon in a natural habitat. J Anim Ecol 64: 75-84

Nakano S, Fausch KD, Kitano S (1999) Flexible niche partitioning via a foraging mode shift: a proposed mechanism for coexistence in stream-dwelling charrs. J Anim Ecol 68: 1079-1092

Nakano S, Furukawa-Tanaka T (1994) Intra- and interspecific dominance hierarchies and variation in foraging tactics of two species of stream-dwelling chars. Ecol Res 9: 9-20 Nagayama S, Kawaguchi Y, Nakano D, Nakamura F (2009) Summer microhabitat partitioning by different size classes of masu salmon (Oncorhynchus masou) in habitats formed by installed large wood in a large lowland river. Can J Fish Aquat Sci 
66: $42-51$

Nislow KH, Folt CL, Parrish DL (1999) Favorable foraging locations for young Atlantic salmon: application to habitat and population restoration. Ecol Appl 9: 1085-1099

Nislow KH, Folt CL, Parrish DL (2000) A spatially explicit bioenergetics analysis of habitat suitability for juvenile Atlantic salmon. T Am Fish Soc 129: 1067-1081

Nislow KH, Folt CL, Seandel M (1998) Food and foraging behavior in relation to microhabitat use and survival of age-0 Atlantic salmon. Can J Fish Aquat Sci 55: $116-127$

Nislow KH, Sepulveda AJ, Folt CL (2004) Mechanistic linkage of hydrologic regime to summer growth of Age-0 Atlantic salmon. T Am Fish Soc 133: 79-88

Piccolo JJ, Hughes NF, Bryant MD (2008) Water velocity influences prey detection and capture by drift-feeding juvenile coho salmon (Oncorhynchus kisutch) and steelhead trout (Oncorhynchus mykiss irideus). Can J Fish Aquat Sci 65: 266-275

Railsback SF, Harvey BC, Hayse JW, LaGory KE (2005) Tests of theory for diel variation in salmonid feeding activity and habitat use. Ecology 86: 947-959

Railsback SF, Hayes JW, LaGory KE (2006) Simulation analysis of within-day flow fluctuation effects on trout below Flaming Gorge Dam. Technical Report. Argonne National Laboratory. Available: www.osti.gov/bridge/.

Railsback SF, Rose KA (1999) Bioenergetics modeling of stream trout growth: temperature and food consumption effects. T Am Fish Soc 128: 241-256

Rosenfeld JS (2003) Assessing the habitat requirements of stream fishes: an overview and evaluation of different approaches. T Am Fish Soc 132: 953-968 
Rosenfeld JS, Boss S (2001) Fitness consequences of habitat use for juvenile cutthroat trout: energetic costs and benefits in pools and riffles. Can J Fish Aquat Sci 58: 585-593

Rosenfeld JS, Leiter T, Lindner G, Rothman L (2005) Food abundance and fish density alters habitat selection, growth, and habitat suitability curves for juvenile coho salmon (Oncorhynchus kisutch). Can J Fish Aquat Sci 62: 1691-1701

Smith RW, Griffith JS (1994) Survival of rainbow trout during their first winter in the Henrys Fork of the Snake river, Idaho. T Am Fish Soc 123: 747-756

Smock LA (2006) Macroinvertebrate dispersal. In: Hauer FR, Lamberti GA (eds) Methods in Stream Ecoogy. Second edition. Academic Press, San Diego, California, pp $465-487$

Spalding S, Peterson NP, Quinn TP (1995) Summer distribution, survival, and growth of juvenile coho salmon under varying experimental conditions of brushy instream cover. T Am Fish Soc 124: 124-130

Urabe H, Nakajima M, Torao M, Aoyama T (2010) Evaluation of habitat quality for stream salmonids based on a bioenergetics model. T Am Fish Soc 139: 1665-1676

Urabe H, Nakano S (1999) Linking microhabitat availability and local density of rainbow trout in low-gradient Japanese streams. Ecol Res 14: 341-349

Wilzbach MA (1985) Relative roles of food abundance and cover in determining the habitat distribution of stream-dwelling cutthroat trout (salmo clarki). Can J Fish Aquat Sci 42: $1668-1672$

Wilzbach MA, Cummins KW, Hall JD (1986) Influence of habitat manipulations on interactions between cutthroat trout and invertebrate drift. Ecology 67: 898-911 
Winstone AJ, Gee AS, Varallo PV (1985) The assessment of flow characteristics at certain weirs in relation to the upstream movement of migratory salmonids. J Fish Biol 27:

$75-83$ 


\section{Figure captions}

Fig. 1 The locations of the study streams, the sampling reaches, and the drift sampling stations.

Fig. 2 Measurements and sampling methods. Panel (a) illustrates a channel unit, including the points for measuring the physical parameters $\left(\mathrm{V}_{\mathrm{fp}}, \mathrm{V}_{\mathrm{fg}}\right.$, and depth) and for calculating the NEI potential. Panel (b) illustrates the length and three widths of a cover feature that were measured for calculating the cover area. The arrangement of the four drift nets in a riffle located near the center of a study reach is illustrated in Panel (c).

Fig. 3 The five possible shape patterns for the capture area (CA) modified from Urabe et al. (2010). We hypothesized that if the bottom velocity is slower than the water column velocity, the fish will remain at the bottom (a); otherwise, the fish will swim at $60 \%$ of the total depth (b). In pattern 1, the maximum capture distance (MCD) minus $3 \mathrm{~cm}$ is less than the depth of the stream; thus, the pattern includes the entire semicircle centered at the focal point. In pattern 2 , in which the depth is lower, a portion of the semicircle is truncated by the stream surface. Pattern 3 consists of a complete circle, pattern 4 is a circle partially truncated by the stream bed, and pattern 5 is a circle partially truncated by both the stream bed and the water surface.

Fig. 4 The relationship between the biomass of the captured fish in the channel unit and the fish biomass estimated by the NEI potential model (a) and the full model (b). 


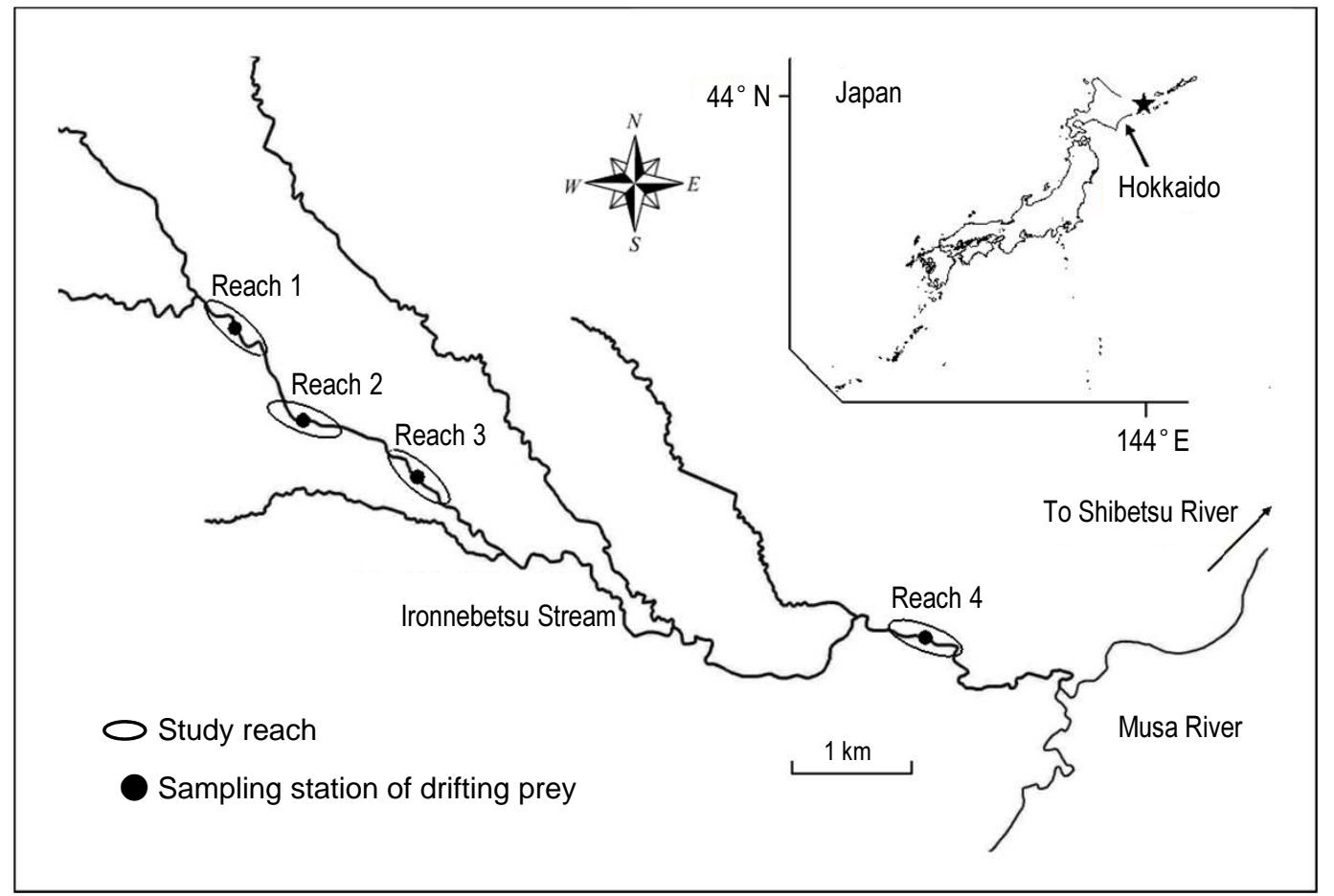

Figure 1. H. Kawai et al. 
(a) Physical variable and NEI potential

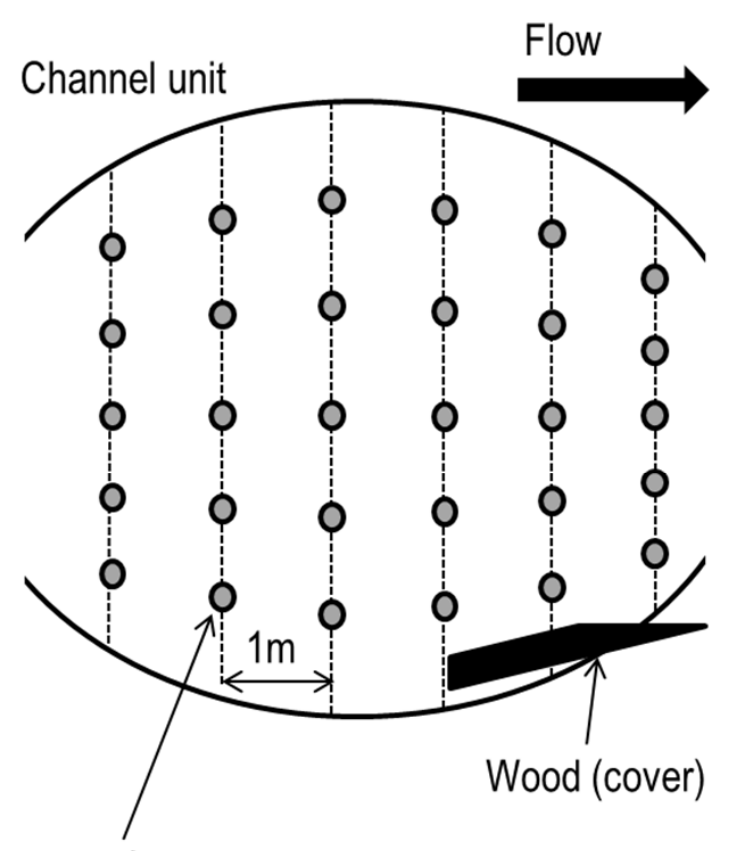

Points for measuring physical parameters

(Vfp, Vfg, and depth) and calculating NEI potential (b) Cover

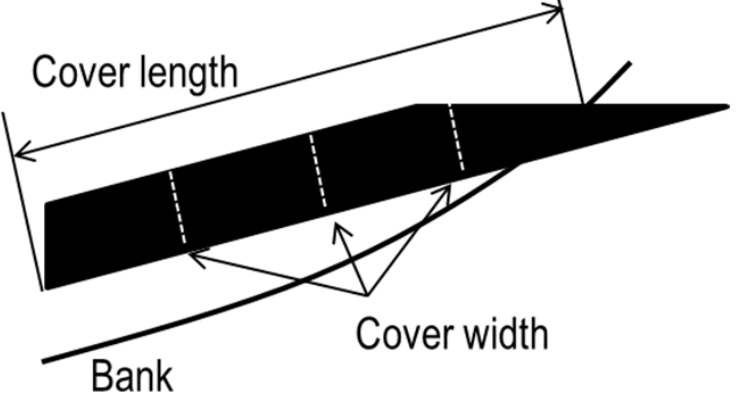

(c) Drifting invertebrate

Riffle located near the center of a study reach

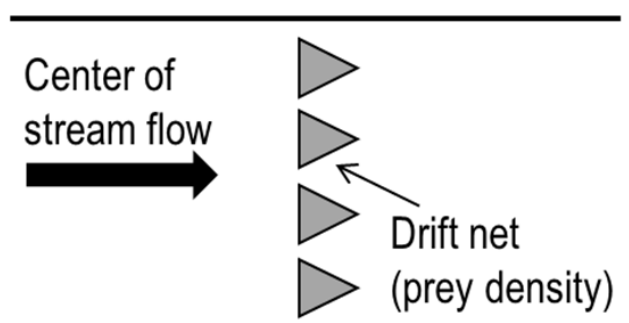

Figure 2. H. Kawai et al. 
(a) Fish stays at the bottom

Water surface

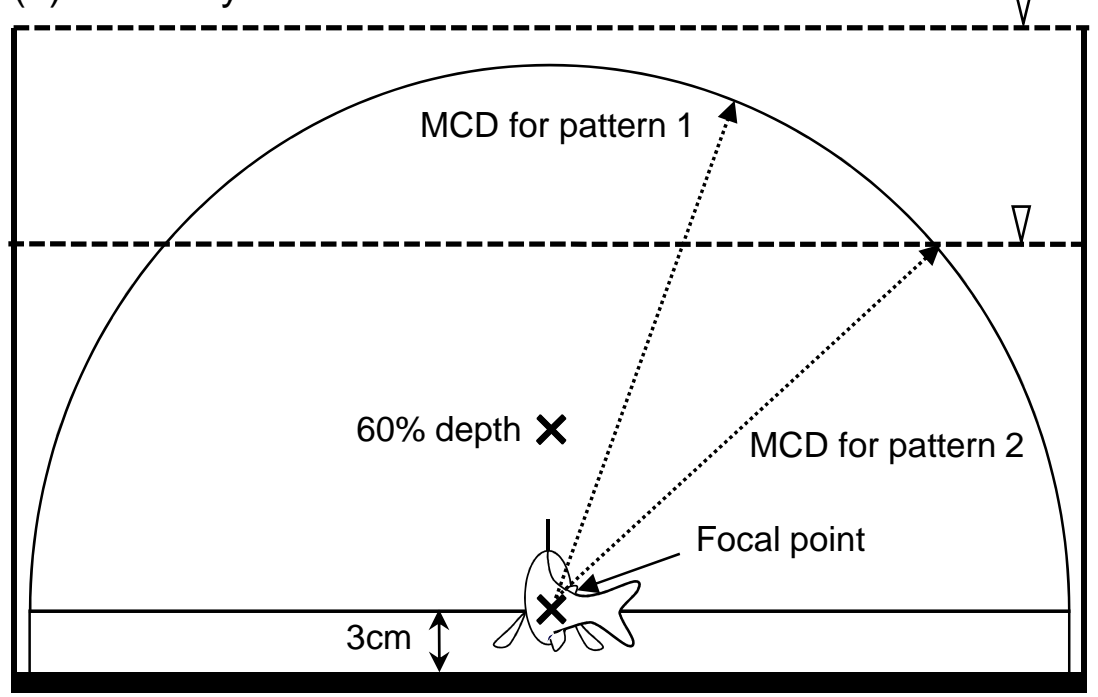

Stream bed

(b) Fish stays at $60 \%$ depth Water surface

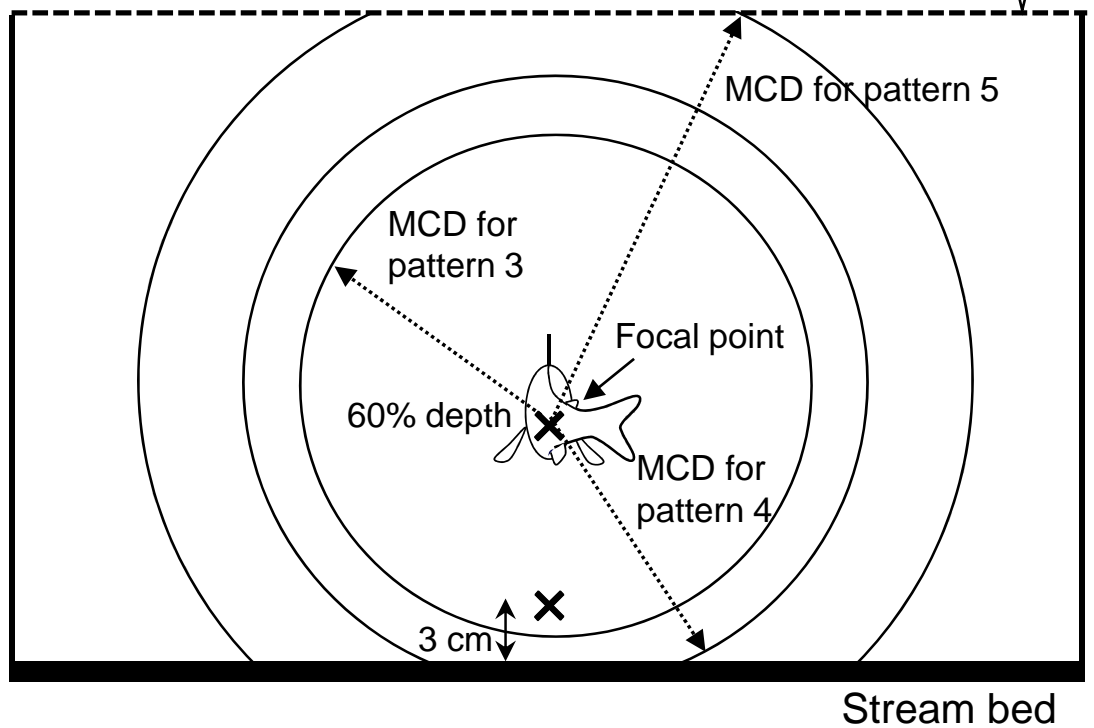

Figure 3. H. Kawai et al. 
(a)

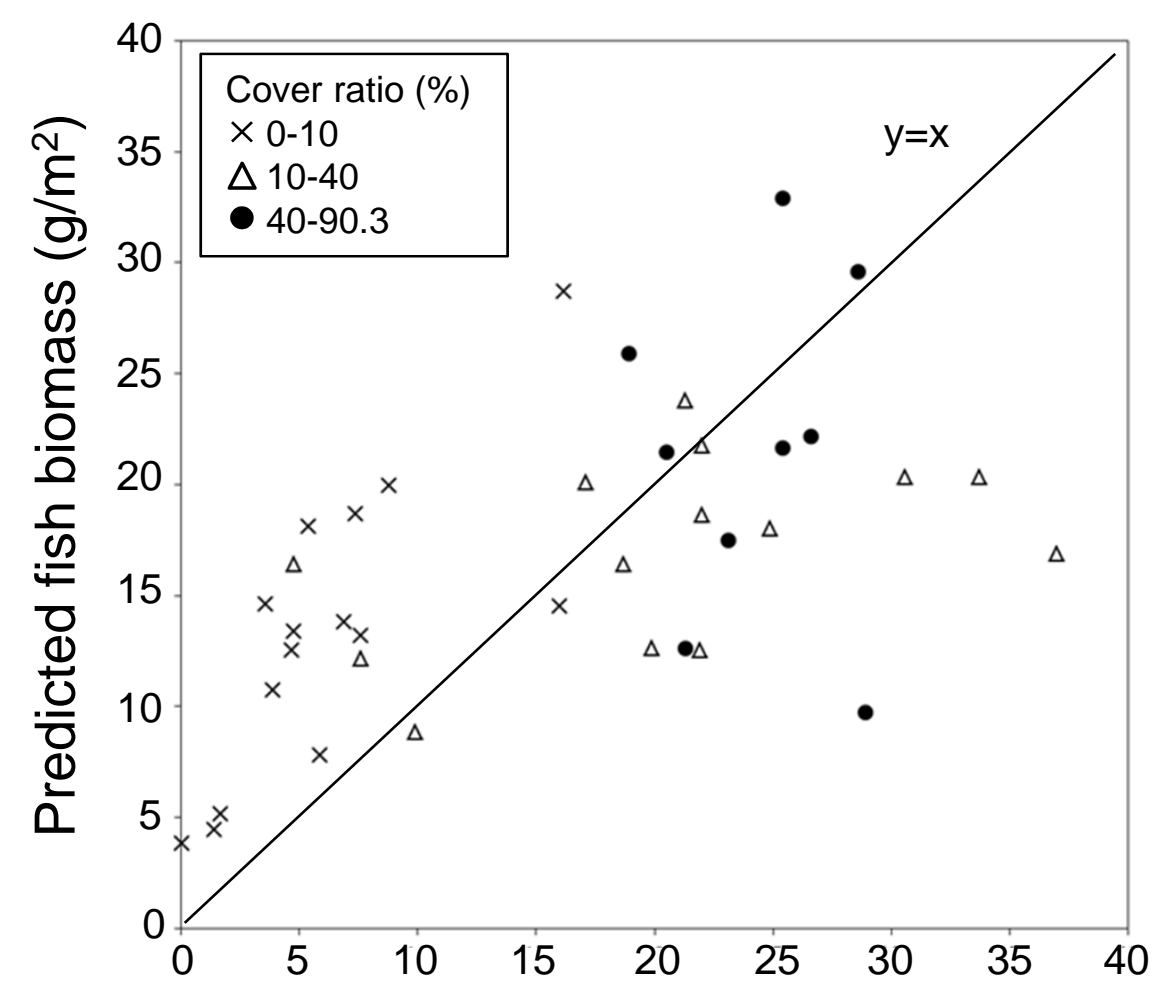

(b)

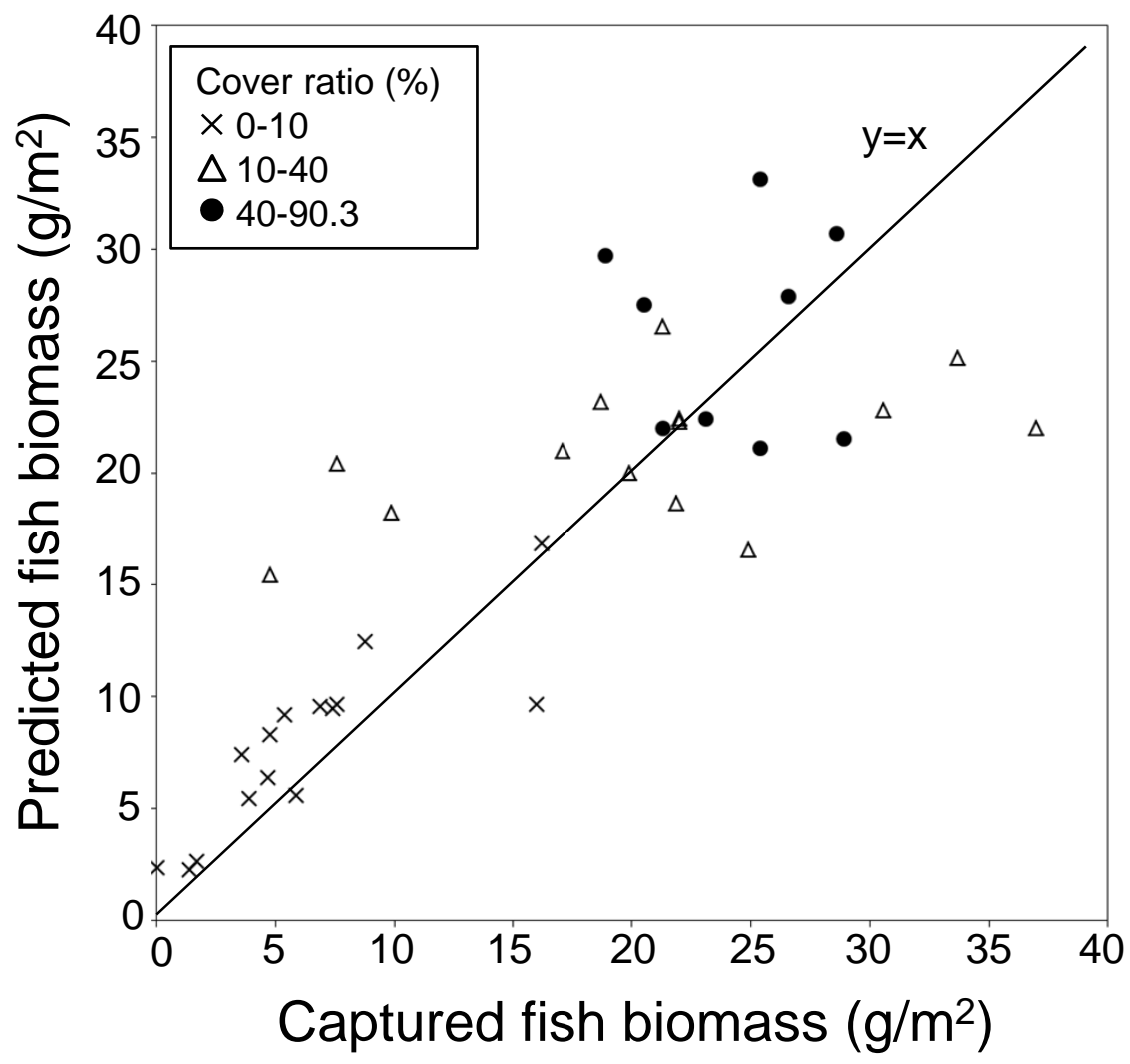

Figure 4. H. Kawai et al. 
Table 1 Equations and values for calculating the NEI at a measuring point $i$. The abbreviations are as follows: $\mathrm{SC}_{i}$, swimming cost $(\mathrm{J} / \mathrm{h})$; $\mathrm{BW}$, mean body weight $(\mathrm{g}) ; \mathrm{V}_{\mathrm{fp} i}$, current velocity at the focal point $(\mathrm{cm} / \mathrm{s}) ; \mathrm{MCD}_{i}$, maximum capture distance $(\mathrm{cm}) ; \mathrm{RD}_{i}$, reaction distance $(\mathrm{cm}) ; \mathrm{V}_{\mathrm{fg}}$, current velocity at the forging point $(\mathrm{cm} / \mathrm{s})$; VMAX, maximum swimming speed of the fish $(\mathrm{cm} / \mathrm{s})$; $P L$, mean prey length $(\mathrm{mm}) ; \mathrm{FL}$, mean fork length $(\mathrm{mm}) ; \mathrm{PE}$, prey energy content $(\mathrm{J} / \mathrm{g}) ; \mathrm{D}$, prey density

\begin{tabular}{lcll}
$\mathrm{Imarameter}^{\mathrm{a}} / \mathrm{m}^{3}$ & Units & Equation or value & Source \\
\hline $\mathrm{SC}_{i}$ & $\mathrm{~J} / \mathrm{h}$ & $\mathrm{SC}_{i}=4.18605 \cdot 0.9906 \cdot \mathrm{BW}^{0.784} \cdot e^{0.0186 \cdot \mathrm{V}_{\mathrm{f}, i}}$ & Fausch (1984) \\
$\mathrm{MCD}_{i}$ & $\mathrm{~cm}$ & $\mathrm{MCD}_{i}=\sqrt{\mathrm{RD}_{i}^{2}-\left(\mathrm{V}_{\mathrm{fg}, i} \cdot \mathrm{RD}_{i} / \mathrm{VMAX}\right)^{2}}$ & Hughes and Dill (1990) \\
$\mathrm{RD}_{i}$ & $\mathrm{~cm}$ & $\mathrm{RD}_{i}=12 \cdot \mathrm{PL}\left(1-e^{-0.2 \cdot \mathrm{FL}}\right)$ & Hughes and Dill (1990) \\
$\mathrm{PE}$ & $\mathrm{J} / \mathrm{g}$ & 20189 & Cummins and Wuycheck (1971) \\
$\mathrm{VMAX}$ & $\mathrm{cm} / \mathrm{s}$ & $\mathrm{VMAX}=10 \cdot \mathrm{FL}$ & Winstone et al. (1985) \\
$\mathrm{BW}$ & $\mathrm{g}$ & $0.6-21.91$ & Field survey data \\
$\mathrm{FL}$ & $\mathrm{mm}$ & $37.7-101.0$ & Field survey data \\
$\mathrm{PL}$ & $\mathrm{mm}$ & $3.65-4.13$ & Field survey data \\
$\mathrm{D}$ & $\mathrm{mg} / \mathrm{m}^{3}$ & $0.0572-0.0709$ & Field survey data \\
\hline
\end{tabular}

${ }^{a} \mathrm{BW}$ and $\mathrm{FL}$ are shown as the range of the averages for each channel unit. $\mathrm{PL}$ and $\mathrm{D}$ are shown as the range of the representative values for each reach (the average at each sampling point). 
Table 2 Prey density, fish biomass, NEI potential, and cover ratio in each channel unit.

\begin{tabular}{|c|c|c|c|c|c|}
\hline Reach & $\begin{array}{c}\text { Channel } \\
\text { unit }\end{array}$ & $\begin{array}{c}\text { Prey density } \\
\left(\mathrm{mg} / \mathrm{m}^{3}\right)\end{array}$ & $\begin{array}{c}\text { Fish biomass } \\
\left(\mathrm{g} / \mathrm{m}^{2}\right)\end{array}$ & $\begin{array}{c}\text { NEI potential } \\
(\mathrm{J} / \mathrm{h})\end{array}$ & $\begin{array}{c}\text { Cover } \\
\text { ratio (\%) }\end{array}$ \\
\hline 1 & Pool & $0.0653 \pm 0.0343$ & 16.56 & $201.5 \pm 151.3$ & 4.0 \\
\hline 1 & Pool & $0.0653 \pm 0.0343$ & 16.67 & $101.8 \pm 121.4$ & 4.0 \\
\hline 1 & Riffle & $0.0653 \pm 0.0343$ & 4.89 & $88.7 \pm 90.0$ & 2.6 \\
\hline 1 & Pool & $0.0653 \pm 0.0343$ & 22.75 & $153.6 \pm 51.1$ & 29.1 \\
\hline 1 & Riffle & $0.0653 \pm 0.0343$ & 4.96 & $123.8 \pm 66.5$ & 13.5 \\
\hline 1 & Pool & $0.0653 \pm 0.0343$ & 18.06 & $173.7 \pm 142.6$ & 22.6 \\
\hline 1 & Riffle & $0.0653 \pm 0.0343$ & 9.87 & $44.1 \pm 54.2$ & 32.2 \\
\hline 1 & Pool & $0.0653 \pm 0.0343$ & 21.91 & $79.4 \pm 87.5$ & 27.1 \\
\hline 1 & Riffle & $0.0653 \pm 0.0343$ & 6.93 & $93.3 \pm 64.9$ & 4.4 \\
\hline 2 & Riffle & $0.0572 \pm 0.0155$ & 0.05 & $11.2 \pm 17.6$ & 0.7 \\
\hline 2 & Pool & $0.0572 \pm 0.0155$ & 25.35 & $145.3 \pm 83.5$ & 14.2 \\
\hline 2 & Riffle & $0.0572 \pm 0.0155$ & 5.90 & $36.5 \pm 51.2$ & 2.7 \\
\hline 2 & Pool & $0.0572 \pm 0.0155$ & 43.03 & $178.7 \pm 96.8$ & 24.5 \\
\hline 2 & Riffle & $0.0572 \pm 0.0155$ & 37.25 & $130.4 \pm 70.6$ & 31.2 \\
\hline 2 & Riffle & $0.0572 \pm 0.0155$ & 18.45 & $79.5 \pm 68.5$ & 31.8 \\
\hline 2 & Riffle & $0.0572 \pm 0.0155$ & 33.72 & $177.3 \pm 99.0$ & 37.4 \\
\hline 2 & Riffle & $0.0572 \pm 0.0155$ & 3.61 & $101.6 \pm 23.4$ & 0.0 \\
\hline 2 & Riffle & $0.0572 \pm 0.0155$ & 4.04 & $61.2 \pm 40.2$ & 0.0 \\
\hline 2 & Riffle & $0.0572 \pm 0.0155$ & 23.45 & $138.4 \pm 60.1$ & 79.4 \\
\hline 3 & Pool & $0.0676 \pm 0.0283$ & 7.61 & $85.8 \pm 99.7$ & 5.2 \\
\hline 3 & Pool & $0.0676 \pm 0.0283$ & 31.31 & $176.8 \pm 130.0$ & 27.9 \\
\hline 3 & Pool & $0.0676 \pm 0.0283$ & 5.16 & $146 \pm 89.5$ & 0.0 \\
\hline 3 & Riffle & $0.0676 \pm 0.0283$ & 1.34 & $13.8 \pm 26.0$ & 0.0 \\
\hline 3 & Pool & $0.0676 \pm 0.0283$ & 28.60 & $51.9 \pm 67.3$ & 59.2 \\
\hline 3 & Riffle & $0.0676 \pm 0.0283$ & 4.71 & $79.4 \pm 59.8$ & 0.0 \\
\hline 3 & Pool & $0.0676 \pm 0.0283$ & 21.31 & $230.4 \pm 128.0$ & 35.6 \\
\hline 3 & Riffle & $0.0676 \pm 0.0283$ & 1.73 & $17.6 \pm 31.9$ & 0.0 \\
\hline 3 & Riffle & $0.0676 \pm 0.0283$ & 7.18 & $75.3 \pm 75.8$ & 34.5 \\
\hline 4 & Pool & $0.0709 \pm 0.0120$ & 16.66 & $315.1 \pm 103.7$ & 4.0 \\
\hline 4 & Riffle & $0.0709 \pm 0.0120$ & 18.93 & $264.6 \pm 123.8$ & 57.8 \\
\hline 4 & Riffle & $0.0709 \pm 0.0120$ & 7.37 & $153.7 \pm 117.3$ & 0.0 \\
\hline 4 & Pool & $0.0709 \pm 0.0120$ & 26.20 & $394.8 \pm 188.3$ & 60.8 \\
\hline 4 & Pool & $0.0709 \pm 0.0120$ & 18.70 & $124 \pm 160.0$ & 37.4 \\
\hline 4 & Riffle & $0.0709 \pm 0.0120$ & 21.34 & $80.1 \pm 119.1$ & 41.6 \\
\hline 4 & Pool & $0.0709 \pm 0.0120$ & 29.53 & $331.5 \pm 145.0$ & 42.6 \\
\hline 4 & Pool & $0.0709 \pm 0.0120$ & 25.37 & $197.2 \pm 123.0$ & 90.3 \\
\hline 4 & Pool & $0.0709 \pm 0.0120$ & 26.65 & $205 \pm 129.1$ & 54.7 \\
\hline 4 & Pool & $0.0709 \pm 0.0120$ & 20.52 & $194.2 \pm 66.1$ & 54.3 \\
\hline
\end{tabular}


Table 3 The results of the AICc from the general linear model for predicting fish biomass.

\begin{tabular}{lccc}
\hline Model & $\mathrm{n}$ & $\mathrm{AICc}$ & $\Delta \mathrm{AICc}$ \\
\hline $\mathrm{NEI}+$ cover & 38 & 262.9 & - \\
cover & 38 & 276.9 & 14.0 \\
$\mathrm{NEI}$ & 38 & 279.1 & 16.3 \\
\hline
\end{tabular}

